University of South Carolina

Scholar Commons

$4-11-2013$

\title{
Chelation Therapy for the Management of Diabetic Complications: A Hypothesis and a Proposal for Clinical Laboratory Assessment of Metal Ion Homeostasis in Plasma
}

\author{
Norma Frizzell \\ University of South Carolina - Columbia, norma.frizzell@uscmed.sc.edu \\ John W. Baynes \\ University of South Carolina - Columbia, john.baynes@sc.edu
}

Follow this and additional works at: https://scholarcommons.sc.edu/biol_facpub

Part of the Biochemistry, Biophysics, and Structural Biology Commons

\footnotetext{
Publication Info

Published in Clinical Chemistry and Laboratory Medicine, Volume 52, Issue 1, 2013, pages 69-75. (C) Clinical Chemistry and Laboratory Medicine 2014, Walter de Gruyter Berlin Boston.
}

This Article is brought to you by the Biological Sciences, Department of at Scholar Commons. It has been accepted for inclusion in Faculty Publications by an authorized administrator of Scholar Commons. For more information, please contact digres@mailbox.sc.edu. 


\section{Perspectives}

Norma Frizzell* and John W. Baynes

\section{Chelation therapy for the management of diabetic complications: a hypothesis and a proposal for clinical laboratory assessment of metal ion homeostasis in plasma}

\begin{abstract}
In a recent article, we presented the hypothesis that decompartmentalized metal ions are a major contributor to the development of diabetic complications and supported the use of chelation therapy for the treatment of diabetic complications [Nagai R, Murray DB, Metz TO, Baynes JW. Chelation: a fundamental mechanism of action of AGE inhibitors, AGE breakers, and other inhibitors of diabetes complications. Diabetes 2012;61:549-59]. Evidence in support of this hypothesis included the observation that many drugs used in the treatment of diabetes are chelators, that advanced glycation end product (AGE) inhibitors and AGE breakers lack carbonyl-trapping or AGE-breaker activity but are potent chelators, and that simple copper chelators inhibit vascular pathology in diabetes and aging. In the present article, we extend this hypothesis, proposing the interplay between copper and iron in the development of pathology in diabetes and other chronic age-related diseases, including atherosclerosis and neurodegenerative diseases. We also discuss the need and provide a framework for the development of a clinical laboratory test to assess plasma autoxidative catalytic activity and transition metal homeostasis in vivo.
\end{abstract}

Keywords: advanced glycation end product (AGE); AGE breaker; AGE inhibitor; autoxidation; chelation; chelation therapy; copper; diabetic complications; metal-catalyzed oxidation; oxidative stress.

*Corresponding author: Norma Frizzell, Department of Pharmacology, Physiology and Neuroscience, University of South Carolina School of Medicine, 3rd floor, VA Building 1, 6439 Garners Ferry Road, Columbia, SC 29208, USA, Phone/Fax: +1-803-216-3521/3538, E-mail: norma.frizzell@uscmed.sc.edu

John W. Baynes: Department of Pharmacology, Physiology and Neuroscience, University of South Carolina School of Medicine, Columbia, SC, USA

\section{Introduction: chelation therapy for diabetic complications}

Advanced glycation end products (AGE) accumulate in long-lived tissue proteins with age and at an accelerated rate in diabetes and other chronic inflammatory diseases $[1,2]$, including atherosclerosis and neurodegenerative diseases. The increase in AGEs develops in parallel with other chemical modifications of proteins, including advanced lipoxidation end products (ALE) and protein oxidation products (PrOP) [3, 4]. Tissue damage accrues not only because of protein chemical modification and cross-linking reactions but also because of inflammatory processes initiated by the interaction of modified proteins with the receptor for AGE as well as scavenger and toll-like receptors [5-7]. Metal-catalyzed autoxidation reactions, i.e., oxidation by molecular oxygen, participate in the formation of ALEs, PrOPs, and most AGEs, supporting the close relationship between oxidative stress and age- and disease-related chemical modification of proteins.

Protein carbonyls are intermediates in the formation of AGEs, ALEs, and PrOPs, and AGE inhibitors such as pyridoxamine actually inhibit the formation of all three classes of chemical modifications of protein [8-10]. However, in a recent Perspectives article in the journal Diabetes [11], we made the following observations.

- There is no evidence that AGE inhibitors actually trap carbonyl or dicarbonyl compounds in vivo or that dicarbonyl cross-links, the putative targets of AGE breakers, actually exist in vivo.

- Chelation is the common mechanism of action of both AGE inhibitors and breakers. Indeed, LR compounds, which have no nucleophilic functional groups with potential carbonyl-trapping activity, are both AGE inhibitors and AGE breakers and have strong chelating activity [12, 13]. 
- Decompartmentalized copper and iron contribute to the development of diabetic complications because these metals catalyze nonenzymatic autoxidation reactions, which are involved in the formation of AGEs, ALEs, and PrOPs.

- Drugs that are commonly used in the management of diabetes, including angiotensin-converting enzyme inhibitors (ACEi), angiotensin-receptor blockers (ARB), other antihypertensive agents (including hydralazine and thiazides), and aldose reductase inhibitors (ARI) are potent chelating agents.

- Consistent with the argument that antidiabetic drugs act as chelators, the copper chelator triethylenetetramine (trientine, TETA) inhibits nephropathy in rodent models of diabetes and also reverses vascular disease in type 2 diabetic animal models and in diabetic patients $[14,15]$.

Based on these observations, we concluded that chronic chelation therapy deserves serious consideration as a clinical tool for the prevention and treatment of diabetic complications. Notably, this therapeutic regimen is distinct from that using intravenous infusion of strong chelators, such as ethylenediaminetetraacetic acid (EDTA), which was recently evaluated in the Trial to Assess Chelation Therapy (TACT), sponsored by the National Center for Complementary and Alternative Medicine and the National Heart Lung and Blood Institute. The preliminary results of the TACT study, suggesting a benefit for diabetic subjects, were released at the 2012 meeting of the American Heart Association and, although still under peer review, have stirred some controversy [16].

Although not stated specifically, it is implicit in the above discussion that there is limited clinical potential for AGE inhibitors or breakers per se in the treatment of diabetic complications; most diabetic patients are already at least partially chelated by an armamentarium of alternative drug therapies, including ACEIs, ARBs, other antihypertensives, and ARIs [11] as well as metformin [17]. The fact that AGE inhibitors and breakers are simply chelators may explain why, more than 25 years since the description of the original AGE inhibitor, aminoguanidine [18], and more than 15 years since the description of the original AGE breaker, phenylthiazolium bromide [19], and despite the introduction of less toxic and more stable AGE inhibitors and breakers since that time [11], not one of these compounds has yet found a place in the clinical toolbox for management of diabetic complications. Although there is strong and incontrovertible evidence that AGE inhibitors and breakers are effective in animal models, except in rare cases, these animals, unlike their human counterparts, are not being treated simultaneously with other drugs. There are also several studies reporting that ACEIs and ARBs alone inhibit AGE formation and that in those instances in which animals are treated with ACEIs and ARBs, AGE inhibitors or breakers provide marginal additional benefit [11]. There is a growing consensus that many different types of drugs used for the treatment of diabetic complications have common downstream effects, including inhibition of inflammation and stimulation of antioxidant defenses, modification of lipid profiles, and inhibition of AGE formation [20,21]. Chelation stands out as the most likely, shared mechanism of action of these drugs. Chelators inhibit the metal-catalyzed production of reactive oxygen species (ROS), thereby inhibiting chemical damage to proteins and subsequent proinflammatory cascades.

\section{Copper and iron in chronic disease}

The formation of AGEs, ALEs, and PrOPs is a manifestation of oxidative stress and autoxidative damage to biomolecules, catalyzed in biological systems by transition metals such as copper and/or iron. These metals are "redox-active", cycling between the oxidized and the reduced state during the generation of ROS by Fenton and Haber-Weiss chemistry. In experiments with the copper chelator trientine, a drug commonly used for treatment of Wilson disease, a copper storage disease, Cooper $[14,15]$ demonstrated that there is more chelatable (loosely bound) copper in the heart of diabetic rats and that TETA promotes increased secretion of copper in urine of diabetic rats and humans, compared with nondiabetic controls. In animal models, TETA caused an increase in vascular elasticity and a decrease in inflammatory biomarkers, and during a 6-month clinical study, trientine inhibited increases in left ventricular mass in type 2 diabetic patients. TETA also inhibited a decrease in aortic elasticity in the streptozotocin-diabetic rat and normalized several biomarkers of inflammation and fibrosis. Baynes and Murray [22] showed that TETA preserved cardiovascular function in the Zucker obese rat, whereas Nagai et al. [23] demonstrated that citric acid, which is a less specific chelator of divalent cations, protected against nephropathy and inhibited AGE formation in the lens of streptozotocin-diabetic rats. In a recent study, Frei and colleagues [24] demonstrated that a chemically unrelated copper chelator, tetrathiomolybdate (TTM), also protected against vascular inflammation and atherogenesis in the apolipoprotein E-deficient, atherosclerosis-prone mouse. 
Although not studied in detail, it is likely that in this case that TTM inhibited the copper-catalyzed autoxidation of lipoproteins, the formation of ALEs, and the activation of macrophages in the vascular wall; although this study did not involve diabetes, it is certain that the process contributes to diabetic vascular disease. Although the effects of TETA on the levels of AGEs, ALEs, or PrOPs in vascular tissue have not been systematically measured, it is clear that this simple chelator, which does not affect blood pressure or blood glucose concentration, may have potential use in diabetes therapy.

TETA and TTM are highly specific copper chelators. Why should chelation of copper alone have such a significant impact in diabetes? Patients with Wilson disease do not develop classic diabetic complications, and iron, rather than copper, overload is more commonly associated with the onset and complications of diabetes [25, 26] as wells as atherosclerosis $[27,28]$ and neurodegenerative diseases [29, 30]. There is little information on the effectiveness of iron chelation on the development of diabetes or its complications, except in iron overload diseases, but iron chelators have shown promise in the treatment of atherosclerosis [31, 32] and neurodegenerative disease [33, 34]. Although iron chelators are not yet commonly used for the clinical management of these diseases, it seems that both iron and copper homeostasis are altered in concert in chronic diseases with an inflammatory component [35, 36], but, as developed below, targeting copper alone seems to be sufficient for controlling oxidative damage in tissues.

Brewer $[37,38]$ has summarized the evidence for the role of inorganic copper in the pathogenesis of age-related diseases, including diabetes, atherosclerosis, Alzheimer disease, and other neurodegenerative diseases. In his discussion, he noted other earlier works [39-41] that observed the development of neurodegenerative disease in rabbits provided with tap water, but not in rabbits given distilled water to drink; those studies [39-41] eventually determined that the neurodegenerative disease was dependent on the copper concentration in the tap water [39, 40], exacerbated by a diet rich in saturated fats [41]. Based on this and other works, Brewer hypothesized that the increase in Alzheimer disease in the Western world results from the introduction of copper plumbing in the early 20th century. Supporting evidence for the central role of copper includes studies with zinc supplementation, which interferes with copper absorption from the intestines, and TTM protection against neurodegenerative disease in animal models $[37,38]$. However, studies on the impact of dietary copper on neurodegenerative diseases in humans are less convincing $[42,43]$, suggesting that it is not copper alone, but other factors in the diet or dysregulation of the metabolism of copper (and/or other metals) that are the source of pathology. Similarly, it is possible that altered copper homeostasis, in concert with hyperglycemia and dyslipidemia of $\beta$-amyloid deposition, may also underlie the progression of tissue damage in diabetes, atherosclerosis, and cardiovascular disease.

\section{Hypothesis}

A standard assay for the copper concentration in buffer solutions measures its activity as a catalyst of oxidation of ascorbic acid [44]. The half-life of ascorbic acid is measured in days in a metal-free buffer or in the presence of strong chelators, such as EDTA. However, the addition of micromolar concentrations of copper decreases the halflife of ascorbate to a matter of minutes. In the presence of protein, this reaction leads to chemical modification, cross-linking, and browning of the protein by Maillard reactions [45]. Iron also catalyzes ascorbate oxidation, yielding ROS by redox cycling reactions under air. Udenfriend and colleagues $[46,47]$ used this reaction for the hydroxylation of aromatic compounds, and Stadtman and colleagues $[48,49]$ showed that iron-catalyzed ascorbate oxidation was a source of AGEs, ALEs, and PrOPs in proteins.

Stumm and Lee [50] (Table 1) demonstrated that copper is a potent catalyst of autoxidation of iron, illustrating the interplay between the redox chemistry of these

Table 1 Effect of copper on rate of oxidation of iron.

\begin{tabular}{rrrr}
\hline $\mathrm{pH}$ & {$\left[\mathrm{Cu}^{2+}\right], \mu \mathrm{M}$} & $\mathrm{Fe}^{+2}$ half-life, $\min$ & $\mathbf{k}_{1}, \mathrm{~min}^{-1}$ \\
\hline 6.56 & 0 & $>120$ & $<0.01$ \\
6.82 & 0 & 30 & 0.023 \\
6.94 & 0 & 12 & 0.058 \\
7.02 & 0 & 8 & 0.086 \\
7.24 & 0 & 4 & 0.17 \\
6.0 & 0 & $>1200$ & $<<0.001$ \\
6.0 & 0.3 & 110 & 0.0063 \\
6.0 & 3 & 60 & 0.012 \\
6.0 & 30 & 40 & 0.017 \\
6.0 & 150 & 20 & 0.035 \\
\hline
\end{tabular}

The rate of autoxidation of ferrous $\left(\mathrm{Fe}^{+2}\right)$ ion in aqueous buffer is first order in $\mathrm{Fe}^{+2}$ concentration (data not shown). The half-life of $\mathrm{Fe}^{+2}$ decreased, and the corresponding first-order rate constant for iron oxidation increased, with increasing $\mathrm{pH}$ (top) and with $\mathrm{Cu}^{2+}$ concentration (bottom). Reaction conditions: initial $\left[\mathrm{Fe}^{+2}\right]=36 \mu \mathrm{M}$, $\mathrm{T}=20.5^{\circ} \mathrm{C}, \mathrm{pO}_{2}=$ ambient, $\mathrm{k}_{1}=$ first-order rate constant for iron oxidation. Data adapted from Howells et al. [51]. 
metals. In an aqueous buffer at neutral $\mathrm{pH}$, cupric $\left(\mathrm{Cu}^{+2}\right)$ ion reacts with ferrous $\left(\mathrm{Fe}^{+2}\right)$ iron to form cuprous $\left(\mathrm{Cu}^{+}\right)$ and ferric $\left(\mathrm{Fe}^{+3}\right)$ ions. $\mathrm{Cu}^{+}$is then spontaneously reoxidized to $\mathrm{Cu}^{+2}$ under air, continuing the catalytic cycle, while $\mathrm{Fe}^{+3}$ is unstable in an aqueous solution at physiological $\mathrm{pH}$, leading to its precipitation from the solution. To explain the effects of copper and iron chelators alone on chronic diseases, we propose that the copper-catalyzed oxidation of iron is responsible for the accumulation of iron in the vascular wall or neuronal plaque (Figure 1), where it serves as a local catalyst of Fenton reactions. These metal-catalyzed, nonenzymatic autoxidation reactions are a source of ROS, including superoxide, peroxide, hydroxyl radicals, and reactive iron-oxo complexes in the extracellular space, contributing to local oxidative stress, protein chemical modification, and inflammation. Not all damage is oxidative, but oxidation dominates the profile of damage; oxidation products include numerous reactive carbonyl and peroxyl species and are clearly recognized by scavenger receptors.

In vivo, it seems likely that chelatable copper is bound loosely to AGEs in the vascular wall or neuronal plaque. Eaton, Monnier, and colleagues $[52,53]$ have shown that AGE proteins, particularly those containing the AGE $N^{\varepsilon}$ (carboxymethyl)lysine (CML), bind copper in a catalytically active form. Based on their structures, it seems likely that other AGE adducts and cross-links in protein, through their amino, carboxyl, hydroxyl, and carbonyl groups, may also have a metal-binding activity. The binding may be weak, but weak binding, without the occupation of all of the metal coordination sites, may in fact activate the metal and facilitate the catalysis of autoxidation reactions,

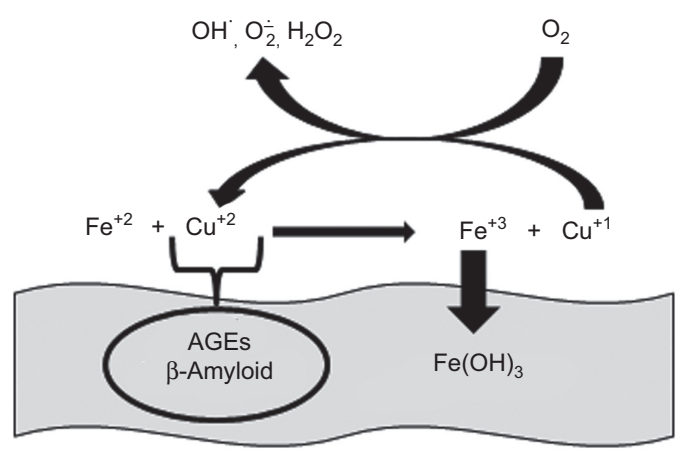

Figure 1 Proposed scheme for the role of decompartmentalized copper in the production of ROS in the vascular wall and in neurodegenerative plaque.

$\mathrm{Cu}^{+2}$ is weakly bound in a redox-active form by tissue AGEs or $\beta$-amyloid protein, where it catalyzes the oxidation of $\mathrm{Fe}^{+2}$ to $\mathrm{Fe}^{+3}$, which precipitates from solution. The reoxidation of $\mathrm{Cu}^{+}$generates ROS: hydroxyl radical, superoxide radical anion, and hydrogen peroxide. Shaded region: plasma membrane or extracellular matrix. as outlined in Figure 1. Analogous to the binding of copper to AGEs in the vascular wall and extracellular matrix in diabetes and atherosclerosis, copper also binds strongly to $\beta$-amyloid proteins in neuronal plaques and in a redoxactive, catalytically active, ROS-generating form [51, 54]. The catalytic role of copper explains the effect of copper chelators alone in treatment of diabetes, atherosclerosis, and neurodegenerative disease and also the enrichment of iron in atherosclerotic and neurodegenerative plaque.

\section{Clinical laboratory assessment of transition metal ion homeostasis}

Oxidative stress is determined by the balance between the rate of generation of ROS and the efficiency of their trapping by antioxidant systems. There are three aspects to this equation, the rate of generation of ROS, the level of antioxidant defenses, and the net damage to tissues, assessed by the measurement of AGEs, ALEs, or PrOPs. Accurate measurement of the latter compounds requires sophisticated and expensive GC- or LC-MS/MS analysis, which is not readily conducted in most clinical chemistry laboratories. A number of assays have been developed for measuring the antioxidant or radical trapping capacity of plasma [55, 56], typically using an oxidant-generating probe and measuring the radical-reducing or radicalscavenging activity of plasma. The rate at which ROS are generated in plasma is less commonly measured, in part because the rate of generation of ROS is low and in part because of the efficient quenching of ROS in plasma. For this reason, it has been difficult to quantify the activity of metal ion catalysts in plasma and the extravascular space. At the same time, the evidence is clear that, based on the effects of chelators and other drugs with chelating activity, decompartmentalized, free metal ions are central to the development of tissue damage in chronic, age-related diseases. It is not the absolute concentration of these ions but their catalytic activity that is relevant - and, unfortunately, difficult to measure.

Blood plasma permeates the extravascular space and the free metal ion concentration in plasma (or cerebrospinal fluid in the case of neurodegenerative diseases) is considered to be in equilibrium with that in the vascular wall and extracellular matrix. Thus, the measurement of free iron and copper in plasma could provide some insight into tissue-bound metal and the level of exposure to ROS generation by these catalytic metal ions. However, the measurement of plasma free iron and copper are not simple procedures in the clinical laboratory. The measurement 
of plasma iron status requires the analysis of total iron, transferrin, ferritin, and iron-binding capacity. Because transferrin and ferritin bind iron with high affinity and $\mathrm{Fe}^{+3}$ precipitates spontaneously from physiological solutions, there is but a negligible fraction of free iron in plasma. Plasma free copper is estimated as the difference between total copper less ceruloplasmin copper. Because approximately $90 \%$ of plasma copper is bound to ceruloplasmin, this assay is based on the difference between two large numbers. McMillin et al. [57] have recently reviewed the limitations of this assay, noting that it is "unreliable and insensitive", yielding "mathematically negative and elevated results in the vast majority of healthy people". These authors also describe a more rigorous assay, using ICP-MS to measure free copper in a plasma ultrafiltrate. Still, these assays provide no indication of the redox activity of the iron or copper in the circulation, i.e., the fraction that functions as catalyst of autoxidation reactions. Considering that iron and copper work in concert to catalyze these reactions, the measurement of either ion alone may provide limited insight into the catalytic activity of plasma, whereas the results of measurement of both may be difficult to interpret. The interpretation may be further complicated by the presence of other metal ions (such as zinc and manganese), amino acids (such as cysteine and histidine), or proteins (such as albumin), which alter the activity of copper and iron in autoxidation reactions.

What is needed for the assessment of plasma redox metal ion homeostasis is an assay of plasma autoxidative catalytic activity (PACA), i.e., the net rate of catalysis of autoxidation reactions and formation of ROS, using a relevant substrate in the plasma. One approach to this assay is to measure the steady-state rate of formation of a glycoxidation product, such as CML or pentosidine, during the incubation of plasma in vitro. The kinetics may be complicated by an early stage during which endogenous antioxidants are consumed, but the rate should stabilize thereafter. An assay of this type has been described by Miyata et al. [58], who measured the rate of AGE formation in control and uremic plasma. Based on this assay, PACA was increased by approximately $150 \%$ in plasma from nondiabetic, uremic subjects, compared with controls. However, the assay involved several weeks' incubation of plasma at $37^{\circ} \mathrm{C}$, followed by acid hydrolysis of proteins and HPLC analysis of pentosidine, a fluorescent Maillard reaction cross-link in proteins. Although the analysis of pentosidine is not readily performed in a clinical laboratory, CML, another glycoxidation product formed in this incubation, might be measured more conveniently by ELISA. The major limitation of the assay, however, it that many artifacts may develop during a multiweek incubation of plasma, including protein denaturation and precipitation and release of copper and iron from plasma proteins (ceruloplasmin, ferritin, transferrin, and others). However, the concept is valuable: this PACA assay does provide a measure of the rate of metal-catalyzed autoxidation reactions. Miyata et al. [59] also observed a 2.5-fold increase in the dehydroascorbate/ascorbate ratio in uremic plasma, which correlated significantly with both free and proteinlinked pentosidine concentration in plasma, suggesting that ascorbate autoxidation was a possible source of the increase in plasma pentosidine in uremia.

It should be possible to increase the sensitivity of this PACA assay and minimize artifacts by the addition of a fixed concentration of ascorbate, which is autoxidized $>1000$-fold more rapidly than glucose and is $10-100$ times more reactive in the formation of AGEs, compared with glucose $[59,60]$. The assay might also be simplified by measuring the changes in total Maillard reaction fluorescence instead of pentosidine alone. An assay of this type, with an appropriate anaerobic control for the nonoxidative generation of fluorophores, should be adaptable to a high-throughput microplate reader. Such an assay should yield a useful index of the activity of plasma metal ion catalytic activity, rather than metal ion concentration, providing a measure of exposure of the vasculature to oxidative stress. The analysis of PACA in the presence of iron- or copper-specific chelators, such as desferrioxamine or TETA may also provide insight into the relative role of these metals in plasma autoxidation reactions. The clinical merits of the assay could be assessed by the comparison of the catalytic activity in the plasma of control and diabetic patients and in diabetic patients with renal and/or vascular complications. The analysis of plasma from diabetic patients on various drug therapies might also provide an index of the efficiency of various antihypertensive and antidiabetic agents, in most cases, chelators as inhibitors of PACA. Overall, the PACA assay would complete the loop describing the status of oxidative stress in plasma, providing an assessment of the rate of generation of ROS to complement the current measures of oxidative damage and antioxidant capacity.

\section{Summary}

In this article, we have briefly summarized the evidence of the involvement of free copper and iron in the development of pathology in three chronic, age-related diseases: diabetes, atherosclerosis, and neurodegenerative diseases. We have proposed a special role for copper as 
a catalyst of iron oxidation and deposition in tissues and, jointly with iron, a role in the production of ROS and a proinflammatory environment in renal, vascular, and neural tissue. We also proposed the development of a method to assess the overall metal-dependent autoxidative activity of plasma, based on the autoxidation of ascorbate. With a better understanding of transition metal homeostasis in plasma and cerebrospinal fluid, it may be possible to develop more effective therapies targeted at the control of oxidative stress and inflammation in chronic diseases.

\section{Conflict of interest statement}

Authors' conflict of interest disclosure: The authors stated that there are no conflicts of interest regarding the publication of this article.

Research funding: None declared.

Employment or leadership: None declared.

Honorarium: None declared.

Received December 14, 2012; accepted March 7, 2013; previously published online April 11, 2013

\section{References}

1. Goh SY, Cooper ME. The role of advanced glycation end-products in progression and complications of diabetes. J Clin Endocrinol Metab 2008;93:1143-52.

2. Negre-Salvayre A, Salvayre R, Auge N, Pamplona R, Portero-Otin M. Hyperglycemia and glycation in diabetic complications. Antiox Redox Signal 2009;11:3071-109.

3. Pamplona R, Naudí A, Gavín R, Pastrana MA, Sajnani G, Ilieva EV, et al. Increased oxidation, glycoxidation, and lipoxidation of brain proteins in prion disease. Free Radic Biol Med 2008;45:1159-66.

4. Pamplona R, Portero-Otín M, Requena J, Gredilla R, Barja G. Oxidative, glycoxidative and lipoxidative damage to rat heart mitochondrial proteins is lower after 4 months of caloric restriction than in age-matched controls. Mech Ageing Dev 2002;123:1437-46.

5. Ramaswamy R, Yan SF, Schmidt AM. The diverse ligand. repertoire of the receptor for advanced glycation endproducts and pathways to the complications of diabetes. Vascul Pharmacol 2012;57:160-7.

6. Horiuchi S, Sakamoto Y, Sakai M. Scavenger receptors for oxidized and glycated proteins. Amino Acids 2003;25: 283-92.

7. Hodgkinson CP, Laxton RC, Patel K, Ye S. Advanced glycation end-product of low density lipoprotein activates the toll-like 4 receptor pathway: implications for diabetic atherosclerosis. Arterioscler Thromb Vasc Biol 2008;28:2275-81.

8. Onorato JM, Jenkins AJ, Thorpe SR, Baynes JW. Pyridoxamine, an inhibitor of advanced glycation reactions, also inhibits advanced lipoxidation reactions. Mechanism of action of pyridoxamine. J Biol Chem 2000;275:21177-84.

9. Chetrykin SV, Mathis ME, Ham AJ, Hachey DL, Hudson BG, Voziyan PA. Propagation of protein glycation damage involves modification of tryptophan residues by reactive oxygen species: inhibition by pyridoxamine. Free Radic Biol Med 2008; 44:1276-85.

10. Chetrykin S, Mathis M, Hayes McDonald W, Shackelford X, Hudson BG, Voziyan PA. Pyridoxamine protects protein backbone from oxidative fragmentation. Biochem Biophys Res Commun 2011;411:574-9.

11. Nagai R, Murray DB, Metz TO, Baynes JW. Chelation: a fundamental mechanism of action of AGE inhibitors, AGE breakers, and other inhibitors of diabetes complications. Diabetes 2012;61:549-59.
12. Rahbar S, Figarola JL. Inhibitors and breakers of advanced glycation endproducts (AGEs): a review. Curr Med Chem Immunol Endocr Metab Agents 2002;2:135-61.

13. Rahbar S, Figarola JL. Novel inhibitors of advanced glycation endproducts. Arch Biochem Biophys 2003;419:63-9.

14. Cooper GJ. Therapeutic potential of copper chelation with triethylenetetramine in managing diabetes mellitus and Alzheimer's disease. Drugs 2011;71:1281-320.

15. Cooper GJ. Selective divalent copper chelation for the treatment. of diabetes mellitus. Curr Med Chem 2012;19:2828-60.

16. Stiles S. TACT: surprising, puzzling benefit from chelation therapy after MI. Available from: www.theheart.org. Accessed 4 November, 2012.

17. Logie L, Harthill J, Patel K, Bacon S, Hamilton DL, Macrae K, et al. Cellular responses to the metal-binding properties of metformin. Diabetes 2012;61:1423-33.

18. Brownlee M, Vlassara H, Kooney A, Ulrich P, Cerami A. Aminoguanidine prevents diabetes-induced arterial wall protein cross-linking. Science 1986;232:1629-32.

19. Vasan S, Zhang X, Zhang X, Kapurniotu A, Berhnagen J, Teichberg $S$, et al. An agent cleaving glucose-derived protein crosslinks in vitro and in vivo. Nature 1996;382:275-8.

20. Coughlan MT, Thallas-Bonke V, Pete J, Long DM, Gasser A, Tong DC, et al. Combination therapy with the advanced glycation end product cross-link breaker, alagebrium, and angiotensin converting enzyme inhibitors in diabetes: synergy or redundancy. Endocrinology 2007;148:886-95.

21. Sourris KC, Harcourt BE, Forbes JM. A new perspective on therapeutic inhibition of advanced glycation in diabetic. microvascular complications: common downstream endpoints achieved through disparate therapeutic approaches. Am J Nephrol 2009;30:323-35.

22. Baynes JW, Murray DB. The metal chelators, trientine and citrate, inhibit the development of cardiac pathology in the Zucker diabetic rat. Exp Diab Res 2009;2009:696378.

23. Nagai R, Nagai M, Shimasaki S, Baynes JW, Fujiwara Y. Citric acid inhibits development of cataracts and ketosis in streptozotocin (type 1) diabetic rats. Biochem Biophys Res Commun 2010;393:118-22.

24. Wei H, Zhang WJ, McMillen TS, LeBoeuf RC, Frei B. Copper chelation by tetrathiomolybdate inhibits vascular inflammation and atherosclerotic lesion development in apolipoprotein E-deficient mice. Atherosclerosis 2012:223:306-13. 
25. Sundararaman S, Vonseca VA, Alam MG, Shah SV. The role of iron in diabetes and its complications. Diabetes Care 2007;30:1926-33.

26. Rajpathak SN, Crandall JP, Wylie-Rosett J, Kabat GC, Rohan TE, Hu FB. The role of iron in type 2 diabetes in humans. Biochim Biophys Acta 2009;1790:671-81.

27. Stanley N, Stadler N, Woods AA, Bannon PG, Davies MJ. Concentrations of iron correlate with the extent of protein, but not lipid, oxidation in advanced human atherosclerotic lesions. Free Radic Biol Med 2006;40:1636-43.

28. Sullivan JL. Iron in arterial plaque: modifiable risk factor for atherosclerosis. Biochim Biophys Acta 2009;1790:718-23.

29. Smith MA, Harris PL, Sayre LM, Perry G. Iron accumulation in Alzheimer disease is a source of redox-generated free radicals. Proc Natl Acad Sci USA 1997;94:9866-8.

30. Castellani RJ, Moreira PI, Perry G, Zhu X. The role of iron as a mediator of oxidative stress in Alzheimer disease. Biofactors 2012;38:133-8.

31. Minqin R, Rajendran R, Pan N, Tan BK, Ong WY, Watt F, et al. The iron chelator desferrioxamine inhibits atherosclerotic lesion development and decreases lesion iron concentrations in the cholesterol-fed rabbit. Free Radic Biol Med 2005;32:1206-11.

32. Zhang WJ, Wei H, Frei B. The iron chelator, desferoxamine, reduces inflammation and atherosclerotic lesions in experimental mice. Exp Biol Med 2010;235:633-41.

33. Hider RC, Roy S, Ma YM, Le-Kong X, Preston J. The potential application of iron chelators for the treatment of neurodegen: erative diseases. Metallomics 2011;3:239-49.

34. Li X, Jankovic J, Le W. Iron chelation and neuroprotection in neurodegenerative diseases. J Neural Transm 2011;118:473-7.

35. Budimir A. Metal ions, Alzheimer's disease and chelation therapy. Acta Pharm 2011;61:1-14.

36. Ayton S, Lei P, Bush Al. Metallostasis in Alzheimer disease. Free Radic Biol Med 2012 Nov 9. doi:pii: S0891-5849(12)01800-X [Epub ahead of print].

37. Brewer GJ. Copper toxicity in Alzheimer's disease: cognitive loss from ingestion of inorganic copper. J Trace Elem Med Biol 2012;26:89-92.

38. Brewer GJ. Metals in the causation and treatment of Wilson's disease and Alzheimer's disease, and copper lowering therapy in medicine. Inorg Chim Acta 2012;393:135-41.

39. Sparks DL, Schreurs BG. Trace amounts of copper in water induce $\beta$-amyloid plaques and learning deficits in a rabbit model of Alzheimer's disease. Proc Natl Acad Sci USA 2003;100:11065-9.

40. Sparks DL, Friedland R, Petanceska S, Schreurs BG, Shi J, Perry G, et al. Trace copper levels in the drinking water, but not zinc or aluminum influence CNS Alzheimer-like pathology. J Nutr Health Aging 2006;10:247-54.

41. Morris MC, Evans DA, Tangney CC, Bienias JL, Schneider JA, Wilson RS, et al. Dietary copper and high saturated and trans fat intakes associated with cognitive decline. Arch Neurol 2006;63:1085-8.

42. Loef $M$, Walach H. Copper and iron in Alzheimer's disease: a systematic review and its dietary implications. Br J Nutr 2012;107:7-19.

43. Eskici G, Axelsen PH. Copper and oxidative stress in the pathogenesis of Alzheimer's disease. Biochemistry 2012;51:6289-311.
44. Buettner GR. Use of ascorbate as a test of catalytic metals in simple buffers. Methods Enzymol 1990;186:125-7.

45. Wolff SP, Jiang ZY, Hunt JV. Protein glycation and oxidative stress in diabetes mellitus and ageing. Free Radic Biol Med 1991;10:339-52.

46. Udenfriend S, Clark CT, Axelrod J, Brodie BB. Ascorbic acid in aromatic hydroxylation. I. A model system for aromatic hydroxylation. J Biol Chem 1954;208:731-39.

47. Brodie BM, Axelrod J, Shore PA, Udenfriend S. Ascorbic acid in aromatic hydroxylation. II. Products formed by reaction of substrates with ascorbic acid, ferrous iron and oxygen. J Biol Chem 1954;208:741-50.

48. Amici A, Levine RL, Tsai L, Stadtman ER. Conversion of amino acid residues in proteins and amino acid homopolymers to carbonyl derivatives by metal-catalyzed oxidation reactions. J Biol Chem 1989;264:3341-6.

49. Refsgaard HH, Tsai L, Stadtman ER. Modifications of proteins by polyunsaturated fatty acid peroxidation products. Proc Natl Acad Sci USA 2000;97:611-6.

50. Stumm W, Lee GF. Oxygenation of ferrous ion. Ind Eng Chem 1961;53:143-6.

51. Howells C, Saar K, Eaton E, Ray S, Palumaa P, Shabala L, et al. Redox-active $\mathrm{CU}(\mathrm{II})$-A $\beta$ causes substantial changes in axonal integrity in cultured cortical neurons in an oxidative-stress dependent manner. Exp Neurol 2012;237:499-506.

52. Qian M, Liu M, Eaton JW. Transitions metals bind to glycated proteins forming redox active "glycochelates": implications for the pathogenesis of certain diabetic complications. Biochem Biophys Res Commun 1998;250:385-9.

53. Saxena P, Saxena AK, Cui XL, Obrenovich M, Gudipaty K, Monnier VM. Transition metal-catalyzed oxidation of ascorbate in human cataract extracts. Possible role of advanced glycation end products. Invest Ophthalmol Vis Sci 2000;41:1473-81.

54. Feaga HA, Maduka RC, Foster MN, Szalai VA. Affinity of Cu+ for the copper binding domain of the $\beta$-amyloid peptide of Alzheimer's disease. Inorg Chem 2011;50:1614-8.

55. Huang D, Ou B, Prior RL. The chemistry behind antioxidant. capacity assays. J Agric Food Chem 2005;53:1841-56.

56. Apak R, Guclu K, Demirata B, Ozyurek M, Celik SE, Bektasoglu B, et al. Comparative evaluation of various total antioxidant capacity assays applied to phenolic compounds with the CUPRAC assay. Molecules 2007;12:1496-547.

57. McMillin GA, Travis JJ, Hunt JW. Direct measurement of free copper in serum or plasma ultrafiltrate. Clin Chem 2009:131:160-5.

58. Miyata T, Ueda Y, Yamada Y, Izuhara Y, Wada T, Jadoul M, et al. Accumulation of carbonyls accelerates the formation of pentosidine, an advanced glycation end product: carbonyl stress in uremia. J Am Soc Nephrol 1998;9:2349-56.

59. Miyata T, Wada T, Cai Z, lida Y, Horie K, Yasuda Y, et al. Implication of an increased oxidative stress in the formation of advanced glycation end products in patients with end-stage renal disease. Kidney Int 1997;51:1170-81.

60. Lee KW, Mossine V, Ortwerth BJ. The relative ability of glucose and ascorbate to glycated and crosslink lens proteins in vitro. Exp Eye Res 1998;67:95-104. 